\title{
A DOMINAÇÃO MASCULINA DE PIERRE BOURDIEU: CRÍTICAS E REFLEXÕES A PARTIR DA PSICOLOGIA ANALÍTICA
}

\author{
Alessandra Munhoz LAZDAN ${ }^{1}$ \\ Fábio Tadeu REINA ${ }^{2}$ \\ Luci Regina MUZZETI ${ }^{3}$ \\ Paulo Rennes Marçal RIBEIRO ${ }^{4}$
}

RESUMO: O presente artigo, de cunho bibliográfico, teve como objetivo fazer uma reflexão da obra $A$ dominação masculina de Pierre Bourdieu a partir dos conceitos da Psicologia Analítica de C. G. Jung. Esta corrente da Psicologia fundamenta-se, entre outras questões, na análise dos princípios masculino e feminino, trazendo um aparato diferenciado para a discussão das ideias trazidas por Bourdieu que envolvem a dominação masculina. A leitura da Psicologia Analítica compreende a questão desta dominação a partir da visão patriarcal da sociedade, corroborando com Bourdieu na questão da submissão que esta cultura impõe à mulher. No entanto, houve contrapontos no tocante à qualidade e validação do referencial feminino, que a teoria bourdieuniana parece desqualificar. Entre as permanências e mudanças das estruturas que reproduzem a ordem masculina, ambas as teorias se mostram concordantes com as atualizações referentes à estrutura patriarcal.

PALAVRAS-CHAVE: Masculino. Psicologia. Sociologia.

\section{Introdução}

Pierre Bourdieu (2002) inicia sua obra A Dominação Masculina alertando o leitor sobre o fato de estarmos inseridos em padrões inconscientes de estruturas históricas da ordem masculina, e que, portanto, nosso olhar e análise estarão sempre sob o viés dessa ótica. Toda sua obra se baseia nesse postulado e é a partir dessa premissa que iremos discorrer algumas questões que se fazem discordantes se tomarmos como contraposto a Psicologia Analítica de C. G. Jung. A escolha por esta vertente da psicologia se deve ao fato de Jung ter dedicado grande parte de sua teoria para a diferenciação entre os princípios masculino e feminino, reconhecendo em cada uma dessas naturezas, qualidades e forças que se fazem complementares. Todavia, assim

\footnotetext{
${ }^{1}$ Mestranda em Educação Sexual. UNESP - Universidade Estadual Paulista. Faculdade de Ciências e Letras - Pós-Graduação em Educação Sexual. Araraquara - SP - Brasil. 14800-901 amlazdan@yahoo.com.br.

2 Docente. UNESP - Universidade Estadual Paulista. Faculdade de Ciências e Letras - Núcleo de Sexualidade. Araraquara - SP - Brasil. 14800-901 - ftreina@ig.com.br.

3 Docente. UNESP - Universidade Estadual Paulista. Faculdade de Ciências e Letras - Núcleo de Sexualidade. Araraquara - SP - Brasil. 14800-901 - lucirm@ fclar.unesp.br.

${ }^{4}$ Coordenador. UNESP - Universidade Estadual Paulista. Faculdade de Ciências e Letras - PósGraduação em Educação Sexual. Araraquara - SP - Brasil. 14800-901 - paulorennes@ fclar.unesp.br.
} 
como Bourdieu, identifica a submissão do princípio feminino na sociedade patriarcal. No entanto, não desqualifica essa natureza, ao contrário do que parece fazer o sociólogo francês, quando afirma categoricamente que toda e qualquer teoria ou prática está subordinada, inconscientemente, à dominação masculina.

No tocante às especificações do que é considerado feminino ou masculino (características não apenas referente ao sexo, mas a atividades e coisas), Bourdieu assinala que foram objetivadas da mesma forma que características homólogas como: alto/baixo, em cima/em baixo, frente/atrás, seco/úmido, claro/escuro, etc. Ele argumenta que

Esses esquemas de pensamento, de aplicação universal, registram como que diferenças de natureza, inscritas na objetividade, das variações e dos traços distintivos (por exemplo, em matéria corporal) que eles contribuem para fazer existir, ao mesmo tempo que as "naturalizam", inscrevendo-as em um sistema de diferenças todas igualmente naturais em aparência; de modo que as previsões que elas engendram são incessantemente confirmadas pelo curso do mundo... (BOURDIEU, 2002, p.15).

Sinaliza algumas formas as quais podemos identificar o que seria o feminino, quais sejam a passividade, a interioridade e a sensibilidade, aspectos estes defendidos pelos anatomistas do séc. XIX, que justificavam a posição social da mulher através de sua anatomia (KNIBIEHLER apud BOURDIEU, 2002). Outras definições ele traz na exposição de ritos de passagem que simbolizam a separação com a mãe, ampliando seus atributos colocando-a em paralelo com a terra, a umidade, a noite e a natureza.

A observação feita por Bourdieu é da organização da sociedade e da visão em torno dela construída a partir das divisões entre masculino e feminino. Afirma que o sistema mítico-ritual reforça e reconhece essa divisão, e que a partição entre os sexos parece estar na ordem das coisas, de forma natural, normal, "ela está presente, ao mesmo tempo, em estado incorporado, nos corpos e nos habitus ${ }^{5}$ dos agentes, funcionando como sistemas de esquemas de percepção, de pensamento e de ação" (BOURDIEU, 2002, p.16).

Ao contrário, segundo o autor, a força masculina dispensa justificativas. A visão androcêntrica se impõe de forma neutra, de maneira que a concebemos como natural,

\footnotetext{
${ }^{5}$ Bourdieu (1983) define habitus como um sistema de disposições que define uma maneira de ser. São estruturas construídas que desencadeiam outras estruturas que compõem a prática e as representações de um indivíduo.
} 
não havendo necessidade, assim, de legitimá-la. A ordem masculina é favorecida pela confirmação constante do funcionamento da sociedade, que constrói o corpo como uma realidade sexuada, seguidora de princípios de divisão sexualizante. Isso quer dizer que o corpo é construído socialmente; é a concepção sexuada do mundo que transfere ao corpo a diferença entre os sexos, que edifica a segmentação entre os gêneros a partir de uma visão mítica ancorada na relação arbitrária de dominação masculina sobre as mulheres.

Juçara T. Cabral (1995), abarcou o referencial mítico para trabalhar a questão da dominação masculina na construção da relação homem-mulher.

De acordo com sua pesquisa, no início da humanidade, existe referência de ter havido um longo período dominado pelo matriarcado. Provavelmente, o que contribuiu para essa vigência, foram os mistérios em torno da mulher, como a menstruação e a procriação, até então, sem o conhecimento de haver a participação masculina. Esses fatos davam grande poder à mulher.

Gradativamente, esse poder começa a declinar com a inserção da participação do homem na teia de relações. A mitologia mostra essa decadência através dos mitos de criação, antes com a origem do mundo a partir de uma deusa e gradualmente um deus é inserido nesta participação, para no fim ser criado por um único deus masculino.

Cabral (1995) analisa que a relação da participação masculina nos mitos de criação e no poder da sociedade pode ter origem na descoberta de sua participação na reprodução, chegando até mesmo a se acreditar que o homem era portador da semente e a mulher somente o receptáculo. Assim, o mistério em torno da mulher foi dissolvido junto com seu poder.

Aristóteles contribuiu com a hegemonia masculina, alegando que o macho era por natureza superior à fêmea e que essa regra era estendida aos gêneros humanos. Também confirmou a ideia do homem ser o único portador da semente para a reprodução humana (CABRAL, 1995).

Para sacramentar a dominação masculina, cria-se o mito judaico-cristão, vigente até hoje. É considerado, inclusive, que os hebreus foram responsáveis pela passagem do matriarcado para o patriarcado. Eva é colocada como inferior desde seu nascimento, originária de uma costela de Adão. Esse dado é interpretado como uma necessidade masculina de não admitir a igualdade dos gêneros. Depois, Eva é a culpada pela expulsão do paraíso e por ter tentado Adão. Eva foi o modelo de mulher trazido ao 
Ocidente, um modelo para não ser seguido. O mito traz no imaginário coletivo o caráter subversivo feminino e a necessidade de se precaver dele (CABRAL, 1995).

Observamos nesse movimento descrito pela autora supracitada, que a hegemonia masculina se deu por meio de um processo de construção. É certo que observamos sua dominação na maior parte das instâncias até os dias de hoje, mas discutiremos a abrangência de sua hegemonia no decorrer do texto.

O princípio masculino passou a ser o referencial para a ordem das coisas após o início do patriarcado. Um exemplo era a representação da vagina como um falo invertido na Idade Média. A anatomia feminina se baseava a partir do corpo masculino. Essa representação obedecia as demais oposições como o positivo/negativo, direito/avesso, sempre respeitando a orientação masculina como norteadora, segundo a pesquisadora Pouchelle citada por Bourdieu (2002).

A identidade masculina, por sua vez, era reconhecida pela virilidade, tanto pelo porte físico, como em questões de honra e ética. Tal postura, seguindo a leitura do autor, é esperada nos homens, evidenciando-se na potência sexual e permeando as fantasias coletivas da potência que deflora e fecunda.

Bourdieu argumenta que a divisão sexual dos corpos vinculou o falo ao princípio do logos, responsável pela atividade pública e ativa do homem, pelo enfrentamento e pela oratória, e que tais exercícios seriam de monopólio masculino.

O falo, segundo Robert Stein (1999), tem a conotação de ação e de penetração a esferas desconhecidas. Seria o elemento agente da iniciativa humana. O falo é também um recurso de ligação, pois tem a força que nos leva de um ponto em direção a um novo objeto ou pessoa. O falo tem conexão com aspectos vitais. Outra vertente ou aspecto do masculino, ou animus $^{6}$, se refere à parte lógica e organizacional, que é representado pelo símbolo de Logos.

Se os símbolos de Logos e o Falo fazem parte das configurações do animus, isso quer dizer que não estamos falando de posturas construídas apenas socialmente, mas de forças presentes na natureza psíquica e que fazem parte do inconsciente coletivo descrito por Jung.

R. Stein (1999) afirma que, a partir da análise de sonhos de muitas mulheres, existe a propensão delas a exigir do homem que ele seja sempre forte e potente,

\footnotetext{
${ }^{6}$ A dimensão masculina é nomeada animus na teoria junguiana e é responsável pelo poder da razão e discriminação. $\mathrm{O}$ animus também é qualificado pela ação, progresso e participação do indivíduo na cultura (JUNG, E., 2003).
} 
inclinando-se a demonstrarem desprezo e até raiva por um homem que se mostre fraco ou indeciso. Esta ideia mostra que sim, tais pré-disposições podem ser reforçadas e ampliadas pelas culturas sociais.

Aqui se encontra a grande armadilha para os homens que se deparam com a exigência da potência fálica: a não permissão para falharem! R. Stein (1999) lembra que nem sempre o falo está ereto. Esta energia pode se encontrar recuada, voltada para o interior, e não para o exterior, como de costume. Adverte que o homem estará fadado a contínuas limitações enquanto associar a ideia de potência ao falo ereto.

R. Stein (1999) corrobora a ideia de C.G Jung e James Hollis (2008) ao confirmar que a libertação do homem desta concepção equivocada de virilidade está na entrega a "estados de passividade, desconhecimento e desamparo como expressões da sua natureza feminina receptiva" (STEIN, 1999, p.163). Ou seja, os autores apontam que existem elementos femininos na psique masculina e que estes são importantes para seu equilíbrio.

Jung formula os conceitos de feminino e masculino a partir de premissas semelhantes que Bourdieu descreve, o que, na visão junguiana, não quer dizer que os conceitos femininos possam ser considerados pejorativos. Jung considera a natureza do princípio feminino tão singular como a do masculino. Além disso, Jung diferencia tais princípios dos conceitos de gênero. Isso se deve ao fato dele reconhecer as instâncias do feminino e masculino presentes em ambos os sexos, portanto, não sendo exclusivas de nenhum gênero.

Carl Gustav Jung (1987) dá o nome de anima à parte feminina do homem. A anima é considerada o referencial de toda a experiência do homem com a mulher, sendo entendida como sua contrassexualidade que se encontra no nível inconsciente masculino. Assim ele explica:

\footnotetext{
Não há homem algum tão exclusivamente masculino que não possua em si algo de feminino. [...] O homem considera uma virtude reprimir da melhor maneira possível seus traços femininos. A repressão de tendências e traços femininos determina um acúmulo dessas pretensões no inconsciente (JUNG, C. G., 1987, p.65).
}

Portanto, para a Psicologia Analítica, o feminino revela qualidades tão essenciais quanto às do falo, que sim, simboliza a potência e atividades próprias do princípio masculino (e não do gênero!). As normas sociais fizeram com que os homens 
reprimissem sua parcela feminina e negligenciassem essa natureza, permitindo, dessa forma, a dominação masculina tal como descrita por Bourdieu.

$\mathrm{O}$ fato de o homem negligenciar a mulher e o feminino pode ter explicação no fato dele interpretar os símbolos (aqui levando-se em conta o Falo e o Logos) de forma concreta. Se os apreendermos metaforicamente, reconheceríamos nesses símbolos sua força, e não sua forma de dominação.

Bourdieu argumenta que a dominação masculina é visível até mesmo nas posições sexuais, lembrando que a posição considerada normal é aquela em que o homem fica por cima da mulher. O autor relata que a posição na qual a mulher se coloca sobre o homem é condenada em várias civilizações. Encontramos dados contrários a este último. De acordo com Gregersen (1983), a primeira posição sexual descrita acima havia sido imposta como correta pelos missionários, sendo considerada a mais comum na cultura ocidental, mas apreciada de forma extremamente grotesca ou estranha em outras culturas, como para os índios Bororó do sul do Brasil, por exemplo, mostrando que as preferências sexuais variam de acordo com cada cultura. Este dado nos ajuda a formular o argumento de que a dominação masculina, ao menos parte de sua abrangência, encontra seus limites e maiores explicações de sua origem e permanência na cultura propriamente patriarcal.

Reconhecemos a expressão pura do masculino e da dominação masculina nas manifestações de exploração e do que traz honra ao homem, como meio de afirmar sua virilidade. $\mathrm{O}$ assédio sexual, por exemplo, pode significar menos uma posse sexual que uma ratificação da dominação. A posse seria o meio de afirmar a dominação (BOURDIEU, 2002).

O autor reafirma sua teoria ao dizer que a relação social de dominação expressa na relação sexual é resposta da divisão construída entre o masculino ativo e o feminino passivo, criando uma sociedade sexuada, como discutido anteriormente. Mas, segundo os teóricos junguianos citados, esta distância e conseqüente dominação tem a possibilidade de minimizar-se com o reconhecimento e amadurecimento das instâncias femininas no próprio homem e de sua importância na sociedade.

Bourdieu assegura que a incorporação da dominação masculina é legitimada pelos ritos de instituição. Ele faz questão de substituir o termo "ritos de passagem" por "ritos de instituição" por acreditar que o primeiro se reduz a uma noção do senso comum. No entanto, embora sua descrição de seu termo pessoal não apresente distinções do termo mais conhecido - sendo nomeado também por "ritos de iniciação" 
dentro da Psicologia - sua interpretação sobre o significado dos ritos recebe conotação divergente desta ciência, pois os interpreta como forma de dominação. Para ele, tais ritos

[...] visam a instaurar, em nome e em presença de toda a coletividade para tal mobilizada, uma separação sacralizante, não só como faz crer a noção de rito de passagem, entre os que já receberam a marca distintiva e os que ainda não a receberam, por serem ainda muito jovens, como também, e sobretudo, entre os que são socialmente dignos de recebê-la e as que delas estão definitivamente excluídas, isto é, as mulheres (BOURDIEU, 2002, p.34, grifo do autor).

Para a Psicologia Analítica, os ritos de passagem ou de separação tem o intuito de separar o menino da dependência materna, para que ele desenvolva sua masculinidade sem a interferência da mãe. Para isso, o garoto passa por provas que variam de acordo com cada cultura, que pode ser desde uma circuncisão - considerada por Bourdieu um rito de instituição da masculinidade - a provas de resistência física, que selam de forma concreta e dolorosa o rompimento com a infância para dar início à vida adulta. Hollis (2008) esclarece que o motivo da existência de tais ritos se explica pelo fato do elemento feminino ser crucial na organização psíquica masculina. O lado feminino, com origem no complexo materno, ou seja, com o estabelecimento da relação com a mãe, confere ao homem um poder forte de atração pela dependência que ele suscita. Assim,

Os ritos de separação eram firmes e poderosos para os rapazes, não apenas por causa do medo do poder do complexo materno, mas também porque se esperava que se separassem do mundo natural, da vida dos instintos, e ingressassem no mundo cultural e artificial fabricado pelo homem (HOLLIS, 2008, p.27).

Nos ritos de separação do homem com a mãe, Bourdieu diz que ela, ou a mulher, recebe uma concepção negativa, sendo definida pela falta, pelo que ela não é. $\mathrm{Na}$ concepção psicológica, o resultado do afastamento feminino não resultaria em conceito negativo apenas, mas seria entendido como algo que se deve manter-se distante devido à força de atração que ela produz, que pode fazer com que o homem regrida aos laços maternos e abrevie seu desenvolvimento. De fato, a conseqüiência do medo masculino pelo elemento feminino lhe acarreta no seu afastamento com os princípios que ela abarca, ou seja, "do relacionamento, do sentimento e da ligação com a força vital" (HOLLIS, 2008, p.49). Portanto, a concepção negativa não significa de forma alguma 
uma falta, ao contrário, inconscientemente o homem conhece a densidade que o feminino comporta. Tais significações são referentes a questões profundas da psique e do desenvolvimento psicológico humano, não sendo fácil sua compreensão nem permitida sua abstração reducionista.

A contenção física a qual a mulher foi submetida, no tocante ao seu comportamento, postura, vestuário, sexualidade, ou seja, toda a disciplina dirigida ao seu corpo, que Bourdieu entende como parte da dominação masculina (e de fato o é), teve sua origem com os mandamentos do cristianismo e legitimado no movimento puritano e principalmente no séc. XIX, época de maior repressão sexual registrada na história (CRAWFORD, 1998; GARTON, 2009). Para Bourdieu, tais gestos femininos perduram até os dias atuais. É certo que a repressão sexual acentuada no vitorianismo do séc. XIX é percebida ainda em nossos corpos, mas a liberdade sexual que evidenciamos atualmente, parece gradualmente se desvincular da dominação masculina bourdieuniana.

Mas o autor contra-argumenta o posicionamento acima, referindo que as mulheres que se mostram salvas da dominação masculina, fazem uso de seu corpo ainda subordinando-o ao ponto de vista masculino, como meio de atrair e seduzir, “[...] adequado a honrar os homens de quem ela depende ou aos quais está ligada [...]" (BOURDIEU, 2002, p.40). Ora, Bourdieu parece honrar aqui a postura típica da moral patriarcal, a qual julga e desqualifica a sexualidade feminina, vulgarizando-a como forma de subordinação masculina. O que dizer da sedução feminina como forma de atração de um parceiro sexual ou como busca de um parceiro para união estável? Será que necessariamente a relação homem-mulher, dentro de uma perspectiva afetivosexual, estaria baseada numa relação de dominação? Novamente, existe o desprezo pelas qualidades femininas, ou da anima, tomando-se o termo junguiano, que contempla qualidades de passividade, receptividade e sensualidade, conceitos os quais não devem ser considerados de forma pura, mas articulados com aspectos masculinos presentes na personalidade da mulher.

Não queremos dizer aqui que a dominação masculina não exista e que as mulheres estão de todo libertas dela, mas a crítica que é feita se refere à sua generalização e à não legitimação de Bourdieu pelas conquistas e qualidades femininas. Ele próprio subjuga as atitudes femininas como sendo sempre subordinadas ao poder masculino. A sentença seguinte mostra parte de seu julgamento: “[...] são elas que, encarregadas das preocupações vulgares da gestão cotidiana da economia doméstica, 
parecem comprazer-se com mesquinharias do cálculo, das contas e dos ganhos que o homem de honra deve ignorar" (BOURDIEU, 2002, p.41).

É provável que essa visão preconceituosa que Bourdieu nos transmite seja decorrente do que ele próprio pontuou que a força que a mulher exerce volta-se contra ela, quando de sua reação ao poder masculino. Considerando-se a confinação a qual a mulher está submetida, as proibições as quais estão sujeitas levam a condutas transgressoras. Toda e qualquer reação feminina acaba por confirmar sua representatividade como seres maléficos e negativos. O preconceito em torno da mulher contaminou sua fala e identidade, tornando-se custosa a reversão desse quadro.

\section{A violência simbólica}

Bourdieu nos chama a atenção para os padrões subjetivos aos quais estamos submetidos e que são objetivados nas relações de dominação do cotidiano. Adotamos as crenças dos dominantes, incorporamos os esquemas de pensamento, produto das relações de poder que se expressam nas oposições da ordem simbólica (masculino/feminino) de forma inquestionável, de maneira natural, constituindo-se assim a violência simbólica. "A violência simbólica se institui por intermédio da adesão que o dominado não pode deixar de conceder ao dominante (e, portanto, à dominação)[...]” (BOURDIEU, 2002, p.46).

Este padrão subjetivo é de tal forma incorporado que ele se manifesta em ações que passam despercebidas, como a escolha da mulher por um homem mais alto e velho do que ela, representando para a mulher a inversão desse cenário como uma sensação de ser diminuída junto de um homem diminuído. Tal argumento se justifica pela procura de maturidade e segurança. Outros sintomas da violência simbólica se manifesta em forma de emoções corporais, como vergonha, humilhação, timidez, culpa, ou também admiração e respeito pelo dominador (BOURDIEU, 2002). De fato, esse padrão se mostra tão internalizado e naturalizado que não percebemos a relação de dominação que está aí embutida. Na psicologia junguiana dizemos que o indivíduo está tomado pelo complexo, ou seja, está inconsciente de sua dominação por toda a configuração que envolve a temática em torno de um símbolo, aqui, a masculina.

Outro ponto importante esclarecido por Bourdieu se refere à dificuldade de desvinculação com as teias da dominação. Isso porque a libertação da submissão não depende apenas da tomada de consciência, uma vez que a dominação é baseada em 
estruturas objetivas, que por sua vez são sustentadas pelos mecanismos que elas desencadeiam e que perpetuam sua reprodução. Se a dominação fosse apenas uma ideologia, a tomada de consciência seria suficiente, mas ela está inscrita igualmente nas coisas e nos corpos. Assim, de acordo com o autor, a ruptura com a dominação simbólica só aconteceria

[...] com uma transformação radical das condições sociais de produção das tendências que levam os dominados a adotar, sobre os dominantes e sobre si mesmos, o próprio ponto de vista dos dominantes. A violência simbólica não se processa senão através de um ato de conhecimento e de desconhecimento prático, ato que se efetiva aquém da consciência [...] (BOURDIEU, 2002, p.53).

O autor aponta que a dominação masculina, ao mesmo tempo em que apresenta privilégios aos homens, oferece igualmente um peso grande a eles. Eles acabam por serem prisioneiros da própria construção social. É imposto ao homem o dever de afirmar constantemente sua virilidade. Este dado foi discutido anteriormente com a contribuição de Hollis (2008). Bourdieu concorda com o fato dos homens temerem reconhecer e assumir elementos delegados ao feminino, como angústia e vulnerabilidade, “[...] sempre expostas à ofensa, as mulheres são também fortes em tudo que representa as armas da fraqueza [...]" (BOURDIEU, 2002, p.63).

Interessante é observar que o ideal de virilidade leva ao paradoxo da vulnerabilidade, por ser humanamente impossível de sustentar tal postura por tempo indeterminado. Por essa razão que a teoria junguiana considera e trabalha com a relação dos opostos. Já era conhecida por Jung a vertente inferior (ou compensatória) de uma atitude unilateral da consciência (JUNG, 1987). Bourdieu (2002) finaliza a reflexão dessa temática concluindo que a virilidade foi construída pelos e para os homens, com o intuito de se voltar contra o feminino, reconhecendo assim, o medo masculino do feminino.

Erich Neumann (2011), psicólogo junguiano que publicou várias obras com a temática do feminino, afirma que este elemento possui, entre outras características já comentadas, a função de transformação na psique masculina, o que iria contrário à tentativa de estabilidade da cultura que os representantes do patriarcado instituem. A formulação do feminino negativo seria uma forma de autoproteção masculina. $\mathrm{O}$ autor sugere que a desvalorização do feminino deve ser entendida como uma tentativa de superação do medo sentido por ele. "O homem quer continuar a ser exclusivamente 
masculino e por medo rejeita o contato transformador com a mulher de status igual ao seu" (NEUMANN, 2011, p.254). Mais uma vez, visualizamos, com a contribuição da Psicologia Analítica, conteúdos positivos e funcionais que o elemento feminino possui e que Bourdieu mostra não reconhecer, sendo de certa forma condescendente à visão patriarcal.

No segundo capítulo da obra intitulado Anamnese das constantes ocultas, Bourdieu ratifica a visão androcêntrica do mundo e questiona o inconsciente histórico presente em todos nós, que para ele, não está ligado à natureza biológica ou psicológica em torno dos postulados sobre os sexos, mas a uma construção histórica que, portanto, seria suscetível de transformação a partir da modificação das condições históricas de sua produção. Ele aponta a educação como facilitadora da criação das desigualdades entre os gêneros, favorecendo os meninos a se implicarem em jogos de dominação.

$\mathrm{O}$ autor pontua as disposições atuais nas quais a dominação se constitui e constrói um mundo hierarquizado, neste momento, de forma invisível, camuflada e inquestionável.

As premissas dominantes estão inscritas, segundo o sociólogo, no ambiente familiar - que se opõe entre o universo público masculino, reconhecido pelos encontros nos bares e clubes - podemos ampliar nos jogos de futebol, pescaria -, e o privado feminino, abreviado no ambiente doméstico.

Estas disposições se ampliam na divisão do trabalho, na escolha das profissões, assim como na hierarquia destas e de suas funções. Por exemplo, a escolha por cargos que exigem submissão e necessidade de segurança, são executados pelas vítimas da dominação de forma a se sentirem satisfeitas com tal tarefa, uma vez que naturalmente possuem qualidades de submissão, gentileza, docilidade, devotamento e abnegação (BOURDIEU, 2002).

Seguindo o mesmo autor, as mulheres seriam orientadas a seguirem carreiras que envolvessem cuidados e desestimuladas a apostarem em carreiras científicas ou técnicas. A visão androcêntrica é injusta mesmo com as mulheres que têm habilidades consideradas masculinas, pois, neste caso, são exigidas, além das habilidades, posturas que elas não teriam por natureza e educação, como a estatura física, voz e aptidões como a agressividade, segurança e a autoridade "natural", recursos que os homens foram treinados ao longo de sua educação. Claramente observamos o envolvimento das relações puras de poder como arbitrárias na escolha masculina para a execução de cargos de chefia. Uma mulher com aptidões de liderança desenvolvidas, poderia 
obviamente exercer esse papel, mas o que está envolvido aqui não é apenas o requisito, mas o poder masculino que não pode ceder seu espaço à mulher.

No tocante à inscrição da dominação nos corpos, Bourdieu aponta a projeção da dicotomia grande/pequeno como referencial para os corpos masculino e feminino. Para os homens, a insatisfação corporal ocorre com as partes pequenas do corpo (o tamanho do pênis é um exemplo clássico), enquanto as mulheres se incomodam com partes grandes de seu corpo, como o quadril ou os peitos. São referenciais construídos que impõem os tipos "normais" e aceitos socialmente.

No entanto, Bourdieu coloca a questão do simbolismo corporal e da dependência em relação ao olhar dos outros como exclusivo das mulheres. Se assim fosse, a preocupação com o porte físico e a exigência de virilidade constante não afetariam os homens como na verdade ocorre. Outro equívoco cometido pelo autor foi delimitar a expectativa do amor romântico ao universo feminino. Anthony Giddens (1993) trabalhou de forma clara essa temática, identificando também nos homens o efeito do mito do amor romântico. Giddens observa que a cisão entre as polaridades do amor puro (decorrente do romantismo) e o sexual para os homens geram discursos e impressões pejorativas e preconceituosas sobre as mulheres. Para o autor, esses discursos mostram a dificuldade dos homens em perder sua hegemonia no controle das relações.

Mais uma questão que não pode ser generalizada se refere à necessidade do olhar do outro para a constituição corporal feminina, colocando-a como vulnerável à aprovação alheia quanto à sua aparência e postura. Bourdieu coloca este fato como universal entre as mulheres. No entanto, a mitologia grega nos oferece outros padrões de disposições femininas que contrariam o postulado do autor francês. A mitologia divide a psicologia feminina em dois grandes grupos; o das deusas vulneráveis e o das deusas virgens. O primeiro se refere às deusas voltadas para o relacionamento e vínculo, que corresponderiam, de certa forma, às características apontadas por Bourdieu. O segundo contempla as deusas que não se pautam na receptividade e na relação, elas teriam características mais masculinas, voltadas para sua independência e ambições próprias. A classificação de virgem significa que elas não estão dispostas a serem penetradas pela dimensão masculina, já que elas próprias contêm tais atributos (BOLEN, 2005).

A visão bourdieuniana mostra se pautar nas configurações passadas da mulher, aquelas originalmente restritas ao ambiente privado e que não tinham a oportunidade de 
manifestar as características das deusas virgens. Atualmente, após as conquistas do movimento feminista, é possível a expressão dos atributos masculinos da mulher.

Neste aspecto, Bourdieu denuncia a visão masculina sobre as mulheres que não respeitam a vulnerabilidade esperada; refere que são vistas como não femininas ou lésbicas. Se agem como homens em posições de poder, arriscam-se a perder a identidade feminina, se agem ao contrário, voltam a corresponder ao padrão conhecido e entendido de forma pejorativa, ou seja, como incapazes e inadaptadas à situação. É a visão androcêntrica que não oferece alternativa para a mulher se comportar da maneira que desejar sem estar livre de julgamento ou classificação. Questionamos a opinião do autor, quando diz que a mulher não está livre da dominação masculina. Seu comportamento muitas vezes mostra estar fora dessa perspectiva, o que ocorre na verdade é a interpretação androcêntrica destorcida sobre seus atos. Aí, sim, a mulher não escapa da visão masculina.

Outro apontamento que pensamos ser pertinente discutir se refere ao pensamento de Bourdieu em relação às funções femininas vulneráveis. A vulnerabilidade em si costuma encerrar qualidades normalmente negativas, provavelmente porque esta pode ser a principal via para se instaurar a dominação. Por outro lado, a vulnerabilidade é também o ingrediente necessário para a formação das relações de vínculo, as quais a mulher, devido a todo seu treinamento para qual é preparada, é mestra. Desejamos defender neste ponto a vertente positiva desta qualidade. É através desta receptividade que a mulher se dispõe a casar (vínculo) e procriar (cuidado), fornecendo a estrutura necessária para a formação e sustentação afetiva de uma família. De fato, tais funções se encontram na esfera do privado, pois envolvem intimidade e acolhimento, ofícios tão necessários quanto à produção e atividades públicas. Tendo dito, a esfera privada, discreta e às vezes silenciosa feminina não deveriam ser palco para discriminação, tampouco para dominação. O fato do universo feminino ser segregado pela visão androcêntrica, não deveria ser ratificado por uma teoria que se propõe crítica, como a bourdieuniana.

A mulher usa da perspicácia da visão feminina para observar os jogos sociais masculinos, os quais ela não faz parte. Bourdieu toma como referência a obra de Virginia Woolf, La promenade au phare, para ilustrar essa relação. A análise que é feita da obra, permite ao autor refletir sobre o teatro social o qual o homem é inserido nas relações de dominação, nas quais ele é protagonista. É função do homem, no papel de pai, mostrar ao filho a dureza e necessidades da vida. Compartilhando da ordem 
cultural, opõe-se da fusão atraente maternal, posicionando-se contra os impulsos da natureza feminina.

Murray Stein (1998) corrobora esta visão bourdieuniana ao trabalhar com as polaridades masculino e feminino, as quais nomeia como consciência solar e lunar respectivamente. Denomina como consciência solar aspectos do masculino referente à consciência patriarcal. Refere-se à internalização das normas, ideais e valores coletivos. Para o autor, a consciência solar é constituída pela cultura e é responsável por manter os padrões culturais vigentes em determinado período. No seu aspecto mais forte, pode assumir a imagem de uma autoridade cuja função é manter estruturas, desviar e canalizar atitudes impulsivas ou instintivas, tal como descritas por Bourdieu como os instintos maternos.

Nas funções culturais às quais o homem é delegado, está embutida a formação do dominante, que compõe o roteiro dos jogos sociais, aqueles instituídos pelos ritos de instituição, e pelos quais o homem é apreendido, tornando-se igualmente vítima de seu próprio jogo. Bourdieu mostra que as mulheres, não fazendo parte desse cenário, “[...] podem até perceber a vaidade daqueles jogos e [...] (consideram) com divertida indulgência os desesperados esforços do 'homem-criança' para se fazer de homem e o infantil desespero em que o jogam suas derrotas" (BOURDIEU, 2002, p.92). Neste ponto, o autor revela que a esposa (personagem da obra) conhecia as fraquezas de seu marido, mas as respeitava, não fazendo uso delas a seu favor. De certa forma, reconhecia a vítima que ele havia se tornado.

A dissimulação da mulher em reconhecer a fraqueza masculina pode ser interpretada como sendo consequência da dominação, mantendo-a em situação de submissão e respeito ao dominante, mesmo tendo um trunfo a seu favor. A mulher pode pressentir, de maneira acertada, que o homem não dá conta de administrar a própria vulnerabilidade. O respeita para ajudá-lo a manter sua hegemonia, mesmo porque ela também pode precisar de sua força e da manutenção de sua estrutura na sociedade. Bourdieu confirma essa análise ao afirmar que a sociedade instrui os homens a “... amar os jogos de poder a as mulheres a amar os homens que jogam" (BOURDIEU, 2002, p.97).

No último capítulo de $A$ dominação masculina, Bourdieu aponta as permanências e mudanças da dominação da atualidade. Um dos pontos de permanência, para o autor, refere-se à luta feminista que acaba por ignorar as relações ocultas de dominação sexual, ao enaltecer suas conquistas em detrimento da cegueira dos reflexos 
da dominação. Este ponto foi discutido anteriormente no tema da violência simbólica, que denuncia as relações de hierarquia sexuada que estão de tal forma naturalizadas que passam despercebidas aos olhares mais críticos.

Bourdieu sinaliza a estranha permanência dos esquemas de dominação, que se mantém apesar das mudanças que afetaram as atividades produtivas e a divisão do trabalho. Refere a esse processo como o trabalho histórico de des-historicização, ou em outras palavras, a "história da (re)criação continuada das estruturas objetivas e subjetivas da dominação masculina" (BOURDIEU, 2002, p.99), que nada mais é que um trabalho histórico de eternização das estruturas de dominação. $\mathrm{O}$ autor aponta que os principais alicerces que sustentam e reproduzem continuamente o poder masculino são a Igreja, o Estado, a família e a escola. O autor alerta que é mais importante analisar o estado do sistema de cada domínio apontado (Igreja, Estado, etc.), os pesos e medidas diferenciados para cada período histórico, do que apenas descrever as transformações das condições das mulheres ou da relação entre os gêneros, pois a primeira parte foi responsável por excluir da história as relações de dominação masculina. Para Bourdieu, as transformações percebidas são decorrentes de transformações nos mecanismos e nas instituições responsáveis pela perpetuação das hierarquias dos gêneros.

A família reproduz a visão masculina e da divisão do trabalho; a Igreja inscreve a negatividade intensa sobre o feminino, agindo de forma simbólica nas estruturas inconscientes e a escola transmite os pressupostos da cultura patriarcal (BOURDIEU, 2002).

O autor observa que, finalmente, a dominação masculina não se impõe mais de forma indiscutível. A dominação não é mais instaurada de forma tão silenciosa ou gratuita, é necessário agora ter justificativa ou defesa para sua instituição. Neste capítulo, ele mostra os contrapontos da atualidade e se curva em reconhecer algumas transformações nas relações de gênero a partir das conquistas da mulher, ou melhor dizendo, a partir de transformações nas disposições estruturantes que perpetuam a dominação.

A mais importante, segundo Bourdieu, foi a escola. O maior acesso das mulheres ao ensino secundário e superior favoreceu sua ascensão no meio social, restringindo sua permanência no ambiente doméstico. A maior autonomia quanto ao próprio corpo, proporcionada principalmente pela pílula anticoncepcional, fez com que o tamanho da família reduzisse e a mulher tivesse maior autonomia de escolha diante o casamento. $\mathrm{O}$ divórcio aumentou, assim como a independência feminina em relação a um homem. 
Ainda sim, o autor sinaliza um paralelo entre uma resistência do habitus da ordem masculina e uma quebra de grande parte dessa dominação por conta das transformações na estrutura da família, a visibilidade de outras formas de sexualidade, como a homossexualidade, o maior acesso da mulher no campo de trabalho, que necessariamente afeta a divisão das atividades domésticas. Foram esses apontamentos que defendemos ao longo do texto e que o autor parecia resistir em reconhecer. Ao final de sua obra, após toda sua exposição e argumentação em relação à dominação masculina, ele pôde se colocar de forma mais leve e dialogar com as novas configurações de família, sexualidade e relações que se apresentam na atualidade.

O que Bourdieu alega como permanência da ordem masculina, refere-se à dificuldade de acesso da mulher aos cargos de poder e às desigualdades na hierarquia das carreiras ingressadas por homens ou mulheres. Neste ponto, o autor parece novamente desqualificar as profissões escolhidas prioritariamente pelas mulheres. Refere que a divisão dos sexos projeta-se sobre a hierarquia das profissões. Aos homens destinam-se as atividades públicas e de poder (áreas de economia e produção tecnológicas) e às mulheres as ocupações de cunho privado (que lembram as funções domésticas e que envolvem cuidados), como serviço social, psicologia, ginecologia e pediatria. Ou elas se envolvem em áreas que ele chama de produção simbólica, como as literárias e artísticas ou jornalismo. O problema não se pauta na inclinação feminina a escolherem tais áreas, mas essas áreas serem desqualificadas por serem predominantemente femininas. Reiteramos aqui o olhar pejorativo e misógino sobre a dimensão feminina (considerando-se a concepção junguiana do termo, por ser mais ampla e não se restringir ao gênero) em todas as propriedades em que ela se faz presente.

Bourdieu parece compreender essa vertente ao fim do capítulo e da obra ao diferenciar as mudanças nas relações entre os gêneros e o panorama social onde é possível visualizar a permanência da ordem masculina. O que causa incômodo é que, ao longo do livro, ele tende a um olhar maciço sobre as mulheres (com um conceito enfraquecedor sobre o feminino), obrigando-nos a sair em suas defesas. De fato, concordamos que a dominação masculina, ou a visão patriarcal, como comumente costumamos nos dirigir na psicologia junguiana, está fortemente enraizada na consciência coletiva e inscrita nos corpos. Contudo, pensamos que as transformações que ocorreram, e ainda ocorrem, no seio da família, e que tiveram seu reflexo na teia de relações no campo do trabalho, possam ter seu prolongamento a longo prazo num 
panorama maior, como o reconhecimento e validação das questões humanas como fonte de potência e equilíbrio para a sociedade.

\section{MASCULINE DOMINATION OF PIERRE BOURDIEU: CRITICAL AND ANALYSES FROM THE ANALYTICAL PSYCHOLOGY}

ABSTRACT: This bibliographical article aimed to analyze the work Masculine domination of Pierre Bourdieu, considering the concepts of Analytical Psychology from C. G. Jung. Among other issues, this psychological theory is based on the analysis of the masculine and feminine principles in order to bring a different apparatus for discussion of the ideas brought by Bourdieu that involves masculine domination. The Analytical Psychology concepts understand this domination from the patriarchal view of society, according to Bourdieu in submission question that this culture imposes on women. However, there were counterpoints regarding the quality and validation of female reference that Bourdieu's theory seems to disqualify. Among the permanencies and changes of the structures that reproduce the masculine order, both theories show agreement with updates regarding the patriarchal structure.

KEYWORDS: Male. Psychology. Sociology.

\section{REFERÊNCIAS}

BOLEN, J. S. As deusas e a mulher: nova psicologia das mulheres. 7.ed. Trad. Maria Lydia Remédio. São Paulo: Paulus, 2005.

BOURDIEU, P. A dominação masculina. 2.ed. Trad. de Maria Helena Kühner. Rio de Janeiro: Bertrand Brasil, 2002.

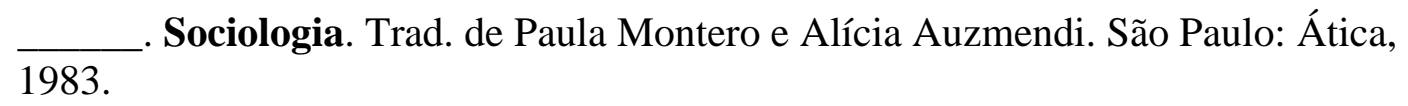

CABRAL, J. T. A sexualidade no mundo ocidental. 2.ed. Campinas: Papirus, 1995.

CRAWFORD, P. Conhecimento sexual na Inglaterra, 1500 - 1750. In: PORTER, R; TEICH, M. (Org.). Conhecimento sexual, ciência sexual: a história das atitudes em relação à sexualidade. Trad. Luiz Paulo Rouanet. São Paulo: Editora Unesp, 1998. p.105-132.

GARTON, S. História da sexualidade: da Antiguidade à revolução sexual. Trad. Mário Félix. Lisboa: Editorial Estampa, 2009.

GIDDENS, A. A transformação da intimidade: sexualidade, amor e erotismo nas sociedades modernas. Trad. Magda Lopes. São Paulo: Ed. da Unesp, 1993.

GREGERSEN, E. Práticas sexuais: a história da sexualidade humana. São Paulo: Roca, 1983. 
HOLLIS, J. Sob a sombra de Saturno: a ferida e a cura dos homens. 3.ed. Trad. Cláudia Gerpe Duarte. São Paulo: Paulus, 2008.

JUNG, C. G. O eu e o inconsciente. 12.ed. Trad. de Dora Ferreira da Silva. Petrópolis: Vozes, 1987.

JUNG, E. Animus e anima. 3.ed. Trad. de Dante Pignatari. São Paulo: Cultrix, 2003.

NEUMANN, E. O medo do feminino: e outros ensaios sobre a psicologia feminina. 2.ed. Trad. de Thereza Christina Stummer. São Paulo: Paulus, 2011.

STEIN, R. Incesto e amor humano: a traição da alma na psicoterapia. Trad. de Cláudia Gerpe Duarte. São Paulo: Paulus, 1999.

STEIN, M. Consciência solar, consciência lunar: ensaio sobre os fundamentos psicológicos da moralidade, da legalidade e da noção de justiça. Trad. de Maria Sílvia Mourão Netto. São Paulo: Paulus, 1998. 